\title{
Positive reappraisal as a stress coping strategy during the COVID-19 pandemic
}

\author{
Juan Pablo Garza Varela, 'Carlos de la Cruz-de la Cruz,' Jessica Giselle Leija Guerrero,' \\ Karen Estefanía Sánchez Rodríguez, ${ }^{1}$ Omar Kawas Valle
}

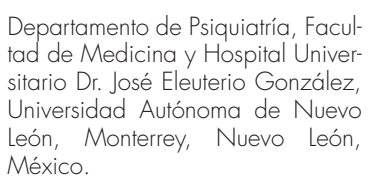

Departamento de Psiquiatría, Facultad de Medicina y Hospital Universitario Dr. José Eleuterio González Universidad Autónoma de Nuevo León, Monterrey, Nuevo León, México.

Correspondence:

Omar Kawas Valle

Departamento de Psiquiatría, Hospital

Universitario Dr. José Eleuterio

González.

Universidad Autónoma de Nuevo León.

Av. Francisco I. Madero

y Av. Gonzalitos s/n,

Col. Mitras Centro,

66460 Monterrey, Nuevo León,

México.

Phone: +52 (81) 8348-0585

Email: okawasvalle@gmail.com

Received: 29 September 2020

Accepted: 11 January 202

Citation:

Garza Varela, J. P., de la Cruz-de la Cruz, C., Leija Guerrero, J. G. Sánchez Rodríguez, K. E., \& Kawas Valle, O. (202 1). Positive reappraisal as a stress coping strategy during the COVID-19 pandemic. Salud Mental, 44(4), 177-184.

DOI: $\underline{10.17711 / \text { SM.0185-3325.2021.023 }}$

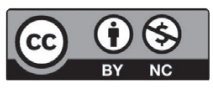

\begin{abstract}
Introduction. The stress coping strategies people rely on impact their psychological well-being and may be related to the risk of developing psychopathology in the short- and long-term after an unfortunate event. Objective. To define the main stress coping strategies in our region as a first step in assessing the risk of developing psychopathology derived from the SARS-CoV-2 pandemic. Method. This is an observational, cross-sectional, analytical study that includes 396 participants over 18 years of age residents of the state of Nuevo Leon. Using an online form, the participants were asked to complete the Coping Strategies Questionnaire (CAE). Results. In general, after two months of mitigation measures in Mexico, positive reappraisal was the stress coping strategy with the highest score in the population studied. We found higher scores on negative auto-focused and overt emotional expression on the comparation between sociodemographic subgroups. Discussion and conclusion. The present study shows that, in our community, positive reappraisal was the stress coping strategy with the highest score. Positive reappraisal is an active form of coping associated with greater psychological well-being and fewer risk of developing psychopathology in the short and long term. Based on this, our hypothesis is that the predominant use of this strategy could translate into a higher psychological well-being during and after the SARS-CoV-2 pandemic in the studied sample.
\end{abstract}

Keywords: Psychological stress, psychological adaptation, COVID-19, coping, Coping Strategies Questionnaire, positive reappraisal.

\section{RESUMEN}

Introducción. Las estrategias de afrontamiento al estrés utilizadas en una situación adversa afectan el bienestar psicológico y pueden influir en el riesgo de desarrollar psicopatología en el corto y largo plazo. Objetivo. Definir las estrategias de afrontamiento al estrés predominantes en nuestra región como primer paso en la valoración del riesgo de desarrollar psicopatología derivada de la pandemia por SARS-CoV-2. Método. Este es un estudio observacional, transversal y analítico, para el cual se reclutó a 396 personas mayores de 18 años, residentes del estado de Nuevo León. Mediante un formulario en línea se pidió a los participantes contestar el Cuestionario de Afrontamiento del Estrés (CAE). Resultados. De forma general, después de dos meses de medidas de mitigación del brote en México, la reevaluación positiva fue la estrategia de afrontamiento al estrés con mayor puntaje en la población estudiada. Encontramos mayores puntajes de autofocalización negativa y expresión emocional abierta en la comparación entre subgrupos sociodemográficos. Discusión y conclusión. El presente estudio muestra que, en nuestra comunidad, la reevaluación positiva fue la estrategia de afrontamiento al estrés con el mayor puntaje. La reevaluación positiva es una forma activa de afrontamiento asociada a mayor bienestar psicológico y menor riesgo de desarrollar psicopatología a corto y largo plazo. Basado en esto, nuestra hipótesis es que el uso predominante de esta estrategia pudiera traducirse en mayor bienestar psicológico durante y posterior a la pandemia por SARS-CoV-2 en la muestra estudiada.

Palabras clave: Estrés psicológico, adaptación psicológica, COVID-19, afrontamiento, Cuestionario de Afrontamiento del Estrés, reevaluación positiva. 


\section{INTRODUCTION}

Over the past 20 years, communities around the globe have been affected by several outbreaks, such as severe acute respiratory syndrome (SARS) in 2002/2003, the H1N1 influenza pandemic in 2009, the Middle East respiratory syndrome (MERS) in 2012, and ebola virus disease in 2016. The physical health impact of each outbreak has been different according to the geographic location, transmission mechanism, infectivity, and mortality of the pathogen (Chew, Wei, Vasoo, Chua, \& Sim, 2020; Rabelo et al., 2016).

In December 2019, the severe acute respiratory syndrome Coronavirus 2 (SARS-CoV-2), a strain that causes coronavirus disease 2019 (COVID-19), was identified in China (Valencia, 2020). According to the John Hopkins Coronavirus Resource Center (2020), as of December 21, 2020, more than 77 million people worldwide had been infected and 1,697,679 had died, whereas in Mexico more than $1,320,545$ cases had been confirmed, with a death toll of 118,202 people. Since March, Mexico's government has enforced mitigation measures to ameliorate the spread of SARS-CoV-2. These include self-isolation, social distancing, hygiene measures, avoiding mass crowds, school closures and suspension of non-essential activities (de la Cruz-de la Cruz, 2020; Limón-Vázquez, Guillén-Ruiz, \& Herrera-Huerta, 2020). In addition to the physical health risk of the pandemic, some of the mitigation measures and psychological distress associated with the outbreak put the population at risk of developing psychopathology (Brooks et al., 2020; Gallagher, Zvolensky, Long, Rogers, \& Garey, 2020). According to the Pan American Health Organization (PAHO), one-third to one-half of the general population exposed to an outbreak will develop psychopathology depending on their vulnerability and experiences with past outbreaks.

In previous epidemics, mental health problems have been recognized in the general population, as well as in patients, caregivers, and health care workers. Regardless of the people affected, mental health problems may persist after the outbreak. Particularly in the general population, the most prevalent have been depression, anxiety, acute stress, and post-traumatic stress disorder (Cai et al., 2020; Chew et al., 2020; Lee \& Lee, 2019). In the current SARS-CoV-2 outbreak, in Mexican population, it is estimated that up to 50\% may present psychological distress, $15 \%$ depressive symptoms, and $22 \%$ anxiety symptoms. Some of these may be stress-related (Limón-Vázquez et al., 2020; Veer et al., 2021).

A stressful experience occurs with an individual struggle related to an obstacle or an imminent threat, like an outbreak (Carver \& Connor-Smith, 2010). To deal with this stressful experiences, each individual builds cognitive and behavioral efforts to reduce, tolerate or master internal or external demands. These are known as coping strategies (Nielsen \& Knardahl, 2014). The concept of coping is broad and has had multiple distinctions over time. One of the first was described by Lazarus and Folkman (1974). According to them, coping strategies are divided into task-oriented (seeking positive reappraisal or solving the problem) and emotion-oriented (seeking a balance in negative emotions through emotional openness or the search for social or emotional support) (Carver \& Connor-Smith, 2010; Smith, Saklofske, Keefer, \& Tremblay, 2015). Eventually, Endler and Parker (1990) suggested a third strategy denominated avoidance-oriented (seeking to appeal to thoughts or activities that intentionally disconnect the individual from stressful situations, [e.g., substance use and abuse and the search for distractions and fantasies]). Another important distinction is between active and passive coping. Through active coping, each individual seeks to engage in adversity using his or her resources to minimize psychological or physical harm. Through task-oriented coping, a sense of coherence is bring about in the individual's life, maintaining optimism, self-control, and a realistic perception of threat. Meanwhile, through passive coping, an individual relies on others for stress solving (Wood \& Bhatnagar, 2015).

The type of strategy used to cope with a stressful event has an impact on the psychological well-being of the individual (Smith et al., 2015; Wood \& Bhatnagar, 2015). Active coping is related to stress resilience (defined as the capacity to maintain or regain mental health despite adversity), whereas passive coping is related to psychopathology vulnerability (Wood \& Bhatnagar, 2015). Emotion-oriented and avoidance-oriented strategies (except constructive emotional openness) are associated with higher perceived stress, helplessness, worse psychological well-being, and a higher risk of depressive and anxiety symptoms (Smith et al., 2015). In contrast, task-oriented coping strategies are associated with lower levels of emotional distress and lower risk of psychopathology (Pozzi et al., 2015). This higher risk of psychopathology in passive forms of coping may be related to the influence of coping strategies in the immune and endocrine response to stress. Passive forms of coping are associated with increased levels of cortisol, contributing to HPA axis deregulation, while active forms are associated with normal cortisol responses and lower levels of pro-inflammatory cytokines (Perez-Tejada et al., 2019).

Also, there is an association between individual personality and culture with coping, and the stability across time of coping strategies. Personality traits may predict the capacity of adjustment of an individual by promoting or interfering with the effectiveness of coping. For example, individuals with high levels of neuroticism may be less prone to solve problems because of high levels of trait-related distress (Carver \& Connor-Smith, 2010). Although the relationship between personality and coping is modest, multiple life stressors may emphasize even the slightest influences. Cultures differ in social structure, norms, and demands, which may influence an individual's coping (See \& Essau, 2010). 
Northamerican and Northern European cultures are considered individualistic, more concerned with individual needs, self-reliance, and independence. In contrast, Mexican culture is considered a collectivistic culture, more concerned with solidarity, maintaining interpersonal relationships, and preserving collective integrity. Collectivistic cultures tend to use more emotion-oriented coping strategies (See \& Essau, 2010). However, in case of disasters, emotion-oriented (seeking support), and task-oriented (positive reappraisal and solving the problem) coping strategies used by Mexican individuals are similar to those used by other individualistic populations (Ibañez, Buck, Khatchikian, \& Norris, 2004). Regarding stability, personality traits tend to be relatively reluctant to change. Meanwhile, coping strategies are less stable over time than personality traits, meaning that coping strategies are malleable. This enables possible interventions in the way an individual copes with stress, improving or adopting healthy and functional coping strategies (Carver \& Connor-Smith, 2010).

Hence, it is important to identify how the general population deals with associated stress during the current SARS-CoV-2 pandemic as a first step in the assessment of individuals at risk of developing psychopathology. We aimed to identify the stress coping strategies most used in our community.

\section{METHOD}

\section{Study design, sample description, and study location}

This was a cross-sectional observational analytical study conducted from May 21 to June 9, 2020, that included participants 18 years or older currently living in Nuevo Leon, Mexico, who agreed to participate in an online survey on Google Forms. We excluded incomplete surveys. Participants were recruited through social network invitations. This study was conducted after two months of sanitary mitigation measures.

\section{Measurements}

We employed the Coping Strategies Questionnaire (Cuestionario de Afrontamiento del Estrés, CAE), originally designed in Spanish by Sandín \& Chorot (2003) and validated in a Mexican sample (González Ramírez \& Landero Hernández, 2007). The questionnaire consists of 42 items assessing seven forms of coping: Problem-solving (FSP), Negative auto-focused (AFN), Positive reappraisal (REP), Overt emotional expression (EEA), Avoidance (EVT), Social support seeking (BAS), and Religious (RLG). These seven strategies considered two dimensions of coping, task-oriented and emotion-oriented coping (González Ramírez \&
Landero Hernández, 2007). Each question provides five possible answers on a Likert scale: 0 (never), 1 (rarely), 2 (sometimes), 3 (frequently), and 4 (almost always).

\section{Procedures}

We asked participants to fill out an anonymous digital form consisting of three sections. The first section asked for demographic data, such as age, gender, marital status, education, occupation, religion, and place of residence. The second consisted of the CAE. The last section provided patients with active coping strategies and contacts of national psychological resources that could be approached if deemed necessary.

We performed accidental non-probabilistic sampling in proximity to our geographic zone. We collected all answered surveys performed during the study period through a database. All the participants gave informed consent for the study, which was obtained before completing the form. We requested an email address at the beginning of the form to avoid participant duplication and removed it once recruitment was completed.

\section{Statistical analysis}

The description of the demographic characteristics of the sample was done with frequencies and percentages for categorical variables, and with medians and interquartile range (IQR) for CAE scores. Normality was assessed by the Kolmogorov-Smirnov test. We compared scores among demographic subgroups with the Mann-Whitney and Friedman tests. Post hoc analyses with Bonferroni correction were performed within significant CAE subscales with multiple demographic subgroups. Demographic subgroups with a minimal sample were excluded from the analysis. The level of statistical significance was set at $p<.05$. Statistical analysis was performed on IBM SSPS version 25 software (IBM Corp., Armonk, NY).

\section{Ethical considerations}

This study was conducted following the general principles stated in the Declaration of Helsinki, with approval from the Ethics in Research Committee of the Facultad de Medicina, Universidad Autónoma de Nuevo León, Mexico (Registration number: PI20-00120).

\section{RESULTS}

\section{Demographic characteristics of the sample}

Four hundred thirty-six participants consented to participate in the online survey. We excluded 40 participants that did 
Table 1

Demographic characteristics of participants

\begin{tabular}{lrc}
\hline Demographic variables & $n$ & $\%$ \\
\hline Total of participants & 396 & 100 \\
Age group & & \\
$\quad$ < 30 years & 299 & 75.5 \\
$\quad$ > 30 years & 97 & 24.5 \\
Gender & & \\
$\quad$ Women & 281 & 71 \\
$\quad$ Men & 113 & 28.5 \\
$\quad$ Nonbinary/third gender & 2 & .5 \\
Currently in a relationship & & \\
$\quad$ No & 323 & 81.6 \\
Yes & 73 & 18.4 \\
Education level & & \\
$\quad$ High school or lower & 37 & 9.3 \\
Graduate or higher & 359 & 90.7 \\
Occupation & & \\
Student & 188 & 47.5 \\
Employee & 165 & 41.7 \\
$\quad$ Unemployed & 43 & 10.8 \\
Religion & & \\
Yes & 297 & 25 \\
No & 99 & \\
\hline
\end{tabular}

not meet the selection criteria. We included a total of 396 participants in the study, with a mean age of 26 (IQR, 2330) years; $71 \%$ were women. Most participants were single $(81.6 \%)$, attained higher education $(90.7 \%)$, were students $(47.5 \%)$ or employees $(41.7 \%)$ or identified with religious practice (75\%), mainly Catholicism (87.2\%). Demographic data are summarized in Table 1.

\section{Coping strategies}

Overall, we found that REP and FSP were the coping strategy subscales that scored highest, with 21 (IQR, 19-24) and 20 (IQR, 17-24), respectively. The RLG subscale reached the lowest score, with 10 (IQR, 7-16) (Table 2). These scores were consistent within demographic subgroups (Table 3).

Table 2

Overall scores in Coping Strategies Questionnaire (CAE) subscales

\begin{tabular}{lc}
\hline Variable & Median (IQR) \\
\hline Positive reappraisal & $21(19-24)$ \\
Problem-solving coping & $20(17-24)$ \\
Avoidance coping & $17(15-20)$ \\
Social support seeking & $16(12-21)$ \\
Negative auto-focused coping & $14(12-17)$ \\
Overt emotional expression & $13(11-16)$ \\
Religious coping & $10(7-16)$ \\
\hline
\end{tabular}

Coping strategies among demographic subgroups

We compared each CAE subscale score to identify slight differences in the application of coping strategies within demographic subgroups (Table 3). Post hoc analysis with Bonferroni correction was employed when necessary and will be stated subsequently.

When compared by age group, we found that FPS scored higher $(p=.003)$ and EEA scored lowest $(p<.001)$ in participants older than 30 . In contrast, participants below 30 scored higher in AFN and lowest in RLG $(p<.001)$. Women tended to score higher in EEA $(p=.006)$ and RLG $(p<.001)$, whereas men scored higher in FPS $(p=.019)$. Participants not currently in a relationship scored higher in $\operatorname{AFN}(p<.001)$ and EEA $(p=.001)$, and lower in FPS $(p=$ $.017)$ and RLG $(p<.001)$. When comparing by education level, we found that participants without higher education (high school or below) scored higher in AFN $(p=.034)$ in comparison to their counterparts. We also found that students scored higher in AFN and EEA $(p<.05)$, and lowest in RLG $(p<.001)$, while unemployed participants scored highest in REP compared to students $(p=.015)$.

\section{DISCUSSION AND CONCLUSION}

In our study, we found that participants yielded the highest scores on positive reappraisal, followed by problem-solving coping, avoidance coping, and social support seeking. These findings had been previously identified as the four most common coping strategies in recent outbreaks around the world (Chew et al., 2020).

In the demographic comparison of our study, we observed CAE score differences among certain groups. Participants over 30 years scored higher in problem-solving coping (an active form of coping), while those under 30 scored higher in negative auto-focused and overt emotional expression (both considered passive forms of coping). These findings approximate to a German population study addressing coping with COVID-19, reporting that older respondents tended to use emotion-oriented coping strategies less (Gerhold, 2020). Furthermore, an optimistic bias and positive reappraisal has been reported to increase with age, by focusing on positive information in a stressful situation and perceiving it as less unpleasant (Carstensen \& Mikels., 2005; Nowlan et al., 2015; Neubauer, Smyth, \& Sliwinski, 2019). Accordingly, we suggest that as age and past experiences increase, adults tend to appraise stressful situations as more manageable, using task-oriented coping.

According to gender, men scored higher in problem-solving and lower in overt emotional expression. Gender and coping strategies are another widely studied topic. Other studies have suggested that men use task-oriented coping strategies more than women, who are more likely to 
Table 3

Comparison of subscale scores between demographic subgroups

\begin{tabular}{|c|c|c|c|c|c|c|c|c|c|c|c|c|c|}
\hline \multirow[b]{2}{*}{ Variable } & \multicolumn{13}{|c|}{ Coping strategies } \\
\hline & & FPS & & $A F N$ & & $R E P$ & & EEA & $E V T$ & & $B A S$ & & $R L G$ \\
\hline \multicolumn{14}{|l|}{ Age group } \\
\hline$\leq 30$ years & 20 & $(16-23)$ & 15 & $(13-18)$ & 21 & $(19-24)$ & 14 & $(12-17)$ & $17(15-20)$ & 16 & $(12-21)$ & 9 & $(6-14)$ \\
\hline$>30$ years & 22 & $(18-24)$ & 13 & $(11-15)$ & 22 & $(20-24)$ & 11 & $(9-14)$ & $17(14-19)$ & 15 & $(11-18)$ & 15 & $(12-20)$ \\
\hline$P$ & & .003 & & $<.01$ & & .41 & & $<.001$ & .173 & & .137 & & $<.001$ \\
\hline \multicolumn{14}{|l|}{ Gender } \\
\hline Women & 20 & $(16-23)$ & 14 & $(12-17)$ & 21 & $(19-24)$ & 14 & $(11-17)$ & $17(15-20)$ & 16 & $(12-21)$ & 12 & $(7-17)$ \\
\hline Men & 21 & $(18-24)$ & 14 & $(12-17)$ & 21 & $(19-24)$ & 13 & $(10-15)$ & $17(15-19.5)$ & 15 & $(11-19.5)$ & & $(6-14)$ \\
\hline$P$ & & .019 & & .675 & & .945 & & .006 & .560 & & .099 & & $<.001$ \\
\hline \multicolumn{14}{|l|}{ Currently in a relationship } \\
\hline Yes & 22 & $(18-24)$ & 13 & $(11-15)$ & 21 & $(19-24)$ & 12 & $(10-15)$ & $16(14-19)$ & 16 & $(12-19)$ & 14 & $(10-20)$ \\
\hline No & 20 & $(16-33)$ & 15 & $(13-18)$ & 21 & $(19-24)$ & 14 & $(11-17)$ & $17(15-20)$ & 16 & $(12-21)$ & & $(6-14)$ \\
\hline$P$ & & .017 & & $<.001$ & & .988 & & .001 & .069 & & .406 & & $<.001$ \\
\hline \multicolumn{14}{|l|}{ Education level } \\
\hline High school or lower & 19 & $(17-22)$ & 15 & $(13-20.5)$ & 20 & $(18-23)$ & 14 & $(12-17)$ & $17(15-19)$ & 16 & $(11-21)$ & & $(6-20)$ \\
\hline Graduate or higher & 20 & $(16-24)$ & 14 & $(12-17)$ & 22 & $(19-24)$ & 13 & $(11-16)$ & $17(15-20)$ & 16 & $(12-20)$ & 10 & $(7-16)$ \\
\hline$P$ & & .169 & & .034 & & .065 & & .274 & .853 & & .933 & & .61 \\
\hline \multicolumn{14}{|l|}{ Occupation } \\
\hline Student & 20 & $(16-23)$ & 15 & $(13-19)$ & 21 & $(19-23)$ & 14 & $(12-17)$ & $17(15-20)$ & 16 & $(12-21)$ & & $(6-13)$ \\
\hline Employee & 20 & $(17-24)$ & 13 & $(12-16)$ & 21 & $(19-24)$ & 13 & $(10-16)$ & $16(14-19)$ & 15 & $(11-19)$ & & $(8-17)$ \\
\hline Unemployed & 22 & $(17-25)$ & 14 & $(12-16)$ & 23 & $(21-25)$ & 12 & $(10-15)$ & $17(14-20)$ & 16 & $(13-22)$ & 16 & $(12-22)$ \\
\hline$P$ & & .129 & & $<.001$ & & .019 & & 0.001 & .075 & & .199 & & $<.001$ \\
\hline \multicolumn{14}{|l|}{ Religion } \\
\hline Yes & 20 & $(16.5-23)$ & 14 & $(12-17)$ & 21 & $(19-24)$ & 13 & $(11-17)$ & $17(15-20)$ & 16 & $(12-21)$ & & $(8-18)$ \\
\hline No & 21 & $(17-24)$ & 14 & $(13-18)$ & 21 & $(19-24)$ & 13 & $(11-16)$ & $17(15-19)$ & 15 & $(12-20)$ & & $(6-8)$ \\
\hline$P$ & & .478 & & .239 & & .724 & & .462 & .789 & & .344 & & $<.001$ \\
\hline
\end{tabular}

Note. FSP, problem-solving coping. AFN, negative auto-focused coping. REP, positive reappraisal. EEA, overt emotional expression. EVT, avoidance coping. BAS, social support seeking. RLG, religious coping. NS, non-significant

employ emotion-oriented coping (Endler \& Parker, 1990; Ptacek, Smith, \& Dodge, 1994; Matud, 2004; Kelly, Tyrka, Price, \& Carpenter, 2008). Meléndez, Mayordomo, Sancho, and Tomás (2012) reported that women tend to score higher in negative auto-focused, overt emotional expression, social support seeking, avoidance, and religious coping. In our study, women scored higher in overt emotional expression and religious coping and lower in problem-solving. These coping differences among gender appear to be socially given. Some authors (Matud, 2004; Ptacek et al., 1994) suggest that society instructs men to use more active coping behaviors, while women are oriented towards more emotion-focused coping. However, Tamres, Janicki, and Helgeson (2002) reported that men do not engage much in task-oriented coping compared to women, while women are more likely to engage in most types of coping on an absolute basis.

We identified higher scores of negative auto-focused coping in participants not currently in a relationship. Previous studies have reported that higher levels of loneliness are associated to more use of emotion-oriented coping strategies, while lower levels relate more to the practice of task-oriented coping (Deckx, van den Akker, Buntinx, \& van Driel, 2018; Fluharty \& Fancourt, 2020).

We also found that participants with higher degrees of education scored lower in negative auto-focused coping. Fluharty and Fancourt (2020) observed that people with higher educational attainment were more inclined to active forms of coping during the COVID-19 pandemic. Also, in recent outbreaks, people with high levels of education had lower overall negative emotions and better mental health (Chew et al., 2020). Educational attainment could have a protective effect on anxiety symptoms related to the current pandemic as lower levels of psychological symptoms have been found in highly educated populations. It appears that people with lower levels of education are more likely to be negatively influenced by unscientific information in social media and television, which may increase the risk of anxiety (Zhao et al., 2020).

Clinically, the most important finding of our study is the higher scores of positive reappraisal in the participants. Positive reappraisal is considered a task-oriented and an active form of coping because it requires reflection to find positive and relevant meaning in an acknowledged and ac- 
cepted negative situation (Perez-Tejada et al., 2019; Nowlan et al., 2016; Smith et al., 2015). It is the most adaptive coping strategy in face of a hostile situation, associated with greater psychological well-being, perceived overall health, life satisfaction, emotional regulation, and lower levels of psychological stress (Chew et al., 2020; González Ramírez \& Landero Hernández, 2007; Master et al., 2009; Nowlan et al., 2016). The continuous use of this strategy can preserve its beneficial effects months or years after the negative event, reducing the risk of depressive and anxiety symptoms (Nowlan et al., 2016). According to the positive appraisal style theory of resilience (PASTOR), the tendency to appraise potential stressors with optimism and realistic expectations on the likelihood of poor outcomes, is the common final pathway for maintained mental health. Positive reappraisal reduces the risk of stress-related mental problems, preventing the inefficient deployment of resources, producing stressful reactions when necessary and avoiding unnecessarily prolonged, or repeated stress (Veer et al., 2021). During past outbreaks, deployment of task-oriented coping strategies in the general population, like positive reappraisal, allowed people to take active steps for empowering themselves, providing a sense of self-control over their health and reducing the uncertainty of the adverse event, developing behaviors that protected them or others, such as adopting infection control measures, obtaining accurate information and positive reappraising their situation. Based on the previous findings, the effect of employing positive reappraisal on the participants of our study could be translated into better coping with stress and a greater degree of psychological well-being during and after the stressful experience.

Besides coping strategies, there are other factors that influence psychological well-being. Age and gender have been reported to be the ones most associated with risk of psychopathology. Previous studies reported that preventive, mandatory, and social confinement had a greater impact on women due the change to teleworking, and taking care and helping their children with online school homework. This sudden change in daily routine contributed to increasing their levels of stress, and risk of depressive or post-traumatic symptoms (Badellino, Gobbo, Torres, \& Aschieri, 2021). Regarding age, younger people, especially between 18-27 years, have been reported with higher risk of anxiety, depression, and post-traumatic symptoms compared to older adults. It is possible that the increase in mental health symptoms is due to less contact with peers, adaptation to online classes, fear of the new reality, and hindered academic progress, or isolation (Badellino et al., 2021; Cao et al., 2020; Li et al., 2020).

Some recommendations could be drawn from this study. In the general population, keeping a daily routine, taking time to reflect on the current situation, maintaining physical activity, writing down the feelings and thoughts, praying, practicing mindfulness, increasing one's knowledge about COVID-19, observing physical distancing recommendations, using facemasks, disinfecting surfaces, reading, watching television, and seeking psychological help if necessary, are positive ways to cope with the pandemic, related to less psychological distress and risk of depressive or post-traumatic stress symptoms (Guo et al., 2020; Shanahan et al., 2020; Balasubramanian, Paleri, Bennett, \& Paleri, 2020).

Task-oriented coping strategies and good stress response recovery are the strongest factors associated with resilience (Veer et al., 2021). Since individuals can change their coping strategies over time and coping strategies are skills that can be practiced and improved, these become target for interventions to improve mental health during the current outbreak. Social support, stress management apps and cognitive behavioral techniques could be used to improve the in-the-moment coping and psychological outcomes of the community (Fluharty \& Fancourt, 2020), especially in high-risk groups, like lonely or younger people.

Our study has multiple limitations. First, the self-selection of study participants may have resulted in a high rate of non-respondents. Also, given the virtual nature of the survey, only those who had electronic media with internet access could participate in the study. This could have caused minor coverage in sectors without access to digital tools. There was also a minor representation and imbalance of certain demographic groups. The majority of participants were female, which may influence finding predominance of active forms of coping. According to Cai et al. (2020), women are more likely to cope with stress in a more adaptive way than men. Similarly, our study recruited a greater proportion of highly educated and employed participants, possibly underestimating the coping strategies employed by other groups. Second, the cross-sectional nature of the study does not allow following up on changes in coping strategies among the general population or generating causal conclusions. Third, our study did not consider the presence of mental disorders or psychological or psychiatric treatments before the pandemic. This is important because a greater negative impact has been reported in people with anxiety or mood disorders (Asmundson et al., 2020) and previous emotional distress has been identified as the strongest risk factor for distress during the current outbreak (Shanahan et al., 2020). Finally, study results may be restricted to the sociocultural, geographic, and temporal context in which the study was conducted, limiting the generalization of results. Owing to these limitations, the results of this study should be approached with caution. Future research could aim to study coping strategies in a major geographic context, considering pre-existing mental problems and studying the stability of these strategies over the course of the pandemic.

In conclusion, task-oriented coping strategies, specifically positive reappraisal, have been reported to be the most 
effective coping strategies in unfavorable events. These strategies do not require changing an adverse situation rather than finding positive meaning despite it. Among the participants of our study, we found higher scores of positive reappraisal. According to the existing literature, people who evaluate stress as a challenge or an opportunity to improve and facilitate the search for goals, cope with stress more effectively and with greater psychological well-being during and after the stressful experience. We must consider that coping strategies are malleable, and unhealthy coping can be modified. It is important to educate and encourage the population to maintain or adopt positive reappraisal as their main long-term coping strategy due the beneficial ongoing effects.

\section{Funding}

None.

\section{Conflict of interest}

The authors declare they have no conflicts of interest.

\section{Acknowledgements}

We are indebted to Luis A. Centeno-Gándara M.D., Adriana Morales-Martínez M.D., Jorge A. Sánchez-Ruíz M.D., Alejandra Grijalva Martínez M.D., Alejandra López Jasso M.C.P., and Sergio-Lozano, M.D. for their observations regarding this manuscript.

\section{REFERENCES}

Asmundson, G., Paluszek, M. M., Landry, C. A., Rachor, G. S., McKay, D., \& Taylor, S. (2020). Do pre-existing anxiety-related and mood disorders differentially impact COVID-19 stress responses and coping? Journal of Anxiety Disorders, 74, 102271. doi: 10.1016/j.janxdis.2020.102271

Badellino, H., Gobbo, M. E., Torres, E., \& Aschieri, M. E. (2021). Early indicators and risk factors associated with mental health problems during COVID-19 quarantine: Is there a relationship with the number of confirmed cases and deaths?. International Journal of Social Psychiatry, 67(5):567-575. doi: $10.1177 / 0020764020966020$

Balasubramanian, A., Paleri, V., Bennett, R., \& Paleri, V. (2020). Impact of COVID-19 on the mental health of surgeons and coping strategies. Head \& Neck, 42(7), 1638-1644. doi: 10.1002/hed.26291

Brooks, S., Webster, R., Smith, L., Woodland, L., Wessely, S., Greenberg, N., \& Rubin, G. (2020). The psychological impact of quarantine and how to reduce It: rapid review of the evidence. The Lancet, 395(10227), 912-920. doi: 10.1016/ SO140-6736(20)30460-8

Cai, H., Tu, B., Ma, J., Chen, L., Fu, L., Jiang, Y., \& Zhuang, Q. (2020). Psychological impact and coping strategies of frontline medical staff in Hunan between January and March 2020 during the outbreak of coronavirus disease 2019 (COVID-19) in Hubei, China. Medical Science Monitor, 26, e924171-1. doi: $10.12659 / \mathrm{msm} .924171$

Cao, W., Fang, Z., Hou, G., Han, M., Xu, X., Dong, J., \& Zheng, J. (2020). The psychological impact of the COVID-19 epidemic on college students in China. Psychiatry Research, 287, 112934. doi: 10.1016/j.psychres.2020.112934

Carstensen, L. L, \& Mikels, J. A. (2005). At the Intersection of Emotion and Cognition: Aging and the Positivity Effect. Current Directions in Psychological Science, 14(3), 117-121. doi: 10.1111/j.0963-7214.2005.00348.x

Carver, C., \& Connor-Smith, J. (2010). Personality and Coping. Annual Review of Psychology, 61(1), 679-704. doi: 10.1146/annurev.psych.093008.100352

Chew, Q. H., Wei, K. C., Vasoo, S., Chua, H. C., \& Sim, K. (2020). Narrative synthesis of psychological and coping responses towards emerging infectious disease outbreaks in the general population: practical considerations for the COVID-19 pandemic. Singapore Medical Journal, 61(7), 350-356. doi: 10.11622/smedj.2020046

de la Cruz-de la Cruz, C. (2020). Medical education and coronavirus disease-19: Current experiences and upcoming challenges to be addressed. Medicina Universitaria, 22(3), 138-139. doi: 10.24875/RMU.20000042

Deckx, L., van den Akker, M., Buntinx, F., \& van Driel, M. (2018). A systematic literature review on the association between loneliness and coping strategies. Psychology, Health \& Medicine, 23(8), 899-916. doi: 10.1080/13548506.2018.1446096

Endler, N. S., \& Parker, J. D. (1990). Multidimensional assessment of coping: A critical evaluation. Journal of Personality and Social Psychology, 58(5), 844854. doi: $10.1037 / 0022-3514.58 .5 .844$

Fluharty, M., \& Fancourt, D. (2020). How have people been coping during the COVID-19 pandemic? Patterns and predictors of coping strategies amongst 26,580 UK adults. PsyArXiv Preprints, 1-22. doi: 10.31234/osf.io/nx7y5

Gallagher, M. W., Zvolensky, M. J., Long, L. J., Rogers, A. H., \& Garey, L. (2020). The Impact of Covid-19 experiences and associated stress on anxiety, depression, and functional impairment in American adults. Cognitive Therapy and Research, 44(6), 1043-1051. doi: 10.1007/s10608-020-10143-y

Gerhold, L. (2020). COVID-19: Risk perception and Coping strategies. Freie Universitat Berlin, 1-11 doi: 10.31234/osf.io/xmpk4

González Ramírez, M. T., \& Landero Hernández, R. (2007). Cuestionario de afrontamiento del estrés (CAE): validación en una muestra mexicana. Revista de Psicopatología y Psicología Clínica, 12(3), 189-198. doi: 10.5944/rppc. vol.12.num.3.2007.4044

Guo, Y., Cao, Q., Hong, Z., Tan, Y., Chen, S., Jin, H. J., ... Yan, Y. (2020). The origin, transmission, and clinical therapies on coronavirus disease 2019 (COVID-19) outbreak - an update on the status. Military Medical Research, 7(11), 1-10. doi: 10.1186/s40779-020-00240-0

Ibañez, G., Buck, C., Khatchikian, N., \& Norris, F. (2004). Qualitative analysis of coping strategies among mexican disaster survivors. Anxiety, Stress \& Coping, 17(1), 69-85. doi: $10.1080 / 10615800310001639628$

Johns Hopkins Coronavirus Resource Center. (2020). COVID-19 by the Center for Systems Science and Engineering (CSSE) at Johns Hopkins University (JHU). [COVID-19 Map]. Retrieved from https://coronavirus.jhu.edu/map.html

Kelly, M. M., Tyrka, A. R., Price, L. H., \& Carpenter, L. L. (2008). Sex differences in the use of coping strategies: predictors of anxiety and depressive symptoms. Depression and Anxiety, 25(10), 839-846. doi: 10.1002/da.20341

Lazarus, R., \& Folkman, S. (1974). Stress, appraisal, and coping. Encyclopedia of Health and Behavior. New York, NY: Springer. AdvancePublication Online. doi: 10.4135/9781412952576.n198

Lee, E., \& Lee, H. (2019). Disaster awareness and coping: Impact on stress, anxiety, and depression. Perspectives in Psychiatric Care, 55(2), 311-318. doi: 10.1111/ ppc. 12351

Li, Y., Wang, Y., Jiang, J., Valdimarsdóttir, U., Fall, K., Fang, F., ... Zhang, W. (2020). Psychological distress among health professional students during the COVID-19 outbreak. Psychological Medicine, 1-3. doi: 10.1017/S0033291720001555

Limón-Vázquez, A., Guillén-Ruiz, G., \& Herrera-Huerta, E. (2020). The Social Isolation Triggered by COVID-19: Effects on Mental Health and Education in Mexico. Health and Academic Achievement. doi: 10.5772/intechopen.93886

Master, S., Amodio, D., Stanton, A., Yee, C., Hilmert, C., \& Taylor, S. (2009). Neurobiological correlates of coping through emotional approach. Brain, Behavior, and Immunity, 23(1), 27-35. doi: 10.1016/j.bbi.2008.04.007

Matud, M. P. (2004). Gender differences in stress and coping styles. Personality and Individual Differences, 37(7), 1401-1415. doi: 10.1016/j.paid.2004.01.010

Meléndez, J., Mayordomo, T., Sancho, P., \& Tomás, J. (2012). Coping strategies: Gender differences and development throughout life span. The Spanish Journal of Psychology, 15(3), 1089-1098. doi: 10.5209/rev_sjop.2012.v15.n3.39399

Neubauer, A., Smyth, J., \& Sliwinski, M. (2019). Age Differences in Proactive Coping With Minor Hassles in Daily Life. The Journals of Gerontology: Series B, 74(1), 7-16. doi: 10.1093/geronb/gby061

Nielsen, M., \& Knardahl, S. (2014). Coping strategies: A prospective study of patterns, stability, and relationships with psychological distress. Scandinavian Journal of Psychology, 55(2), 142-150. doi: 10.1111/sjop.12103 
Nowlan, J., Wuthrich, V., \& Rapee, R. (2015). Positive reappraisal in older adults: a systematic literature review. Aging \& Mental Health, 19(6), 475-484. doi: 10.1080/13607863.2014.954528

Nowlan, J., Wuthrich, V., \& Rapee, R. (2016). The impact of positive reappraisal on positive (and negative) emotion among older adults. International Psychogeriatrics, 28(4), 681-693. doi: 10.1017/s1041610215002057

Perez-Tejada, J., Garmendia, L., Labaka, A., Vegas, O., Gómez-Lazaro, E., \& Arregi, A. (2019). Active and Passive Coping Strategies: Comparing psychological distress, cortisol, and proinflammatory cytokine levels in breast cancer survivors. Clinical Journal of Oncology Nursing, 23(6), 583-590. doi: 10.1188/19.cjon.583-590

Pozzi, G., Frustaci, A., Tedeschi, D., Solaroli, S., Grandinetti, P., Di Nicola, M., \& Janiri, L. (2015). Coping strategies in a sample of anxiety patients: factorial analysis and associations with psychopathology. Brain and Behavior, 5(8),1-10. doi: $10.1002 / \mathrm{brb} 3.351$

Ptacek, J. T., Smith, R. E., \& Dodge, K. L. (1994). Gender differences in coping with stress: When stressor and appraisals do not differ. Personality and Social Psychology Bulletin, 20(4), 421-430. doi: 10.1177/0146167294204009

Rabelo, I., Lee, V., Fallah, M., Massaquoi, M., Evlampidou, I., ... Severy, N. (2016). Psychological Distress among ebola survivors Discharged from an ebola Treatment Unit in Monrovia, Liberia - A Qualitative study. Frontiers in Public Health, 4, 142. doi: 10.3389/fpubh.2016.00142

Sandín, B., \& Chorot, P. (2003). Cuestionario de afrontamiento del estrés (CAE): desarrollo y validación preliminar. Revista de Psicopatología y Psicología Clínica, 8(1), 39-53. doi: 10.5944/rppc.vol.8.num.1.2003.3941

See, C. M., \& Essau, C. A. (2010). Coping Strategies in Cross-Cultural Comparison. In: Mayer B., Kornadt HJ. (eds). Psychologie - Kultur - Gesellschaft (pp. 161173). VS Verlag für Sozialwissenschaften. doi: 10.1007/978-3-531-92212-6_7
Shanahan, L., Steinhoff, A., Bechtiger, L., Murray, A., Nivette, A., Hepp, U., ... Eisner, M. (2020). Emotional distress in young adults during the COVID-19 pandemic: evidence of risk and resilience from a longitudinal cohort study. Psychological Medicine, 1-10. doi: 10.1017/s003329172000241x

Smith, M., Saklofske, D., Keefer, K., \& Tremblay, P. (2015). Coping strategies and psychological outcomes: The moderating effects of personal resiliency. The Journal of Psychology, 150(3), 318-332. doi: 10.1080/00223980.2015.1036828

Tamres, L., Janicki, D., \& Helgeson, V. (2002). Sex differences in coping behavior: A meta-analytic review and an examination of relative coping. Personality and Social Psychology Review, 6(1), 2-30. doi: 10.1207/s15327957pspr0601_1

Valencia, D. N. (2020) Brief Review on COVID-19: The 2020 Pandemic Caused by SARS-CoV-2. Cureus, 12(3), e7386. doi: 10.7759/cureus.7386

Veer, I. M., Riepenhausen, A., Zerban, M., Wackerhagen, C., Puhlmann, L., Engen, H., ...Kalisch, R. (2021). Psycho-social factors associated with mental resilience in the Corona lockdown. Translational Psychiatry, 11, 67. doi: 10.1038/s41398020-01150-4

Wood, S. K., \& Bhatnagar, S. (2015). Resilience to the effects of social stress: Evidence from clinical and preclinical studies on the role of coping strategies. Neurobiology of Stress, 1, 164-173. doi: 10.1016/j.ynstr.2014.11.002

Zhao, H., He, X., Fan, G., Li, L., Huang, Q., Qiu, Q., ... Xu, H. (2020). COVID-19 infection outbreak increases anxiety level of general public in China: involved mechanisms and influencing factors. Journal of Affective Disorders, 276, 446452. doi: $10.1016 /$ j.jad.2020.07.085 